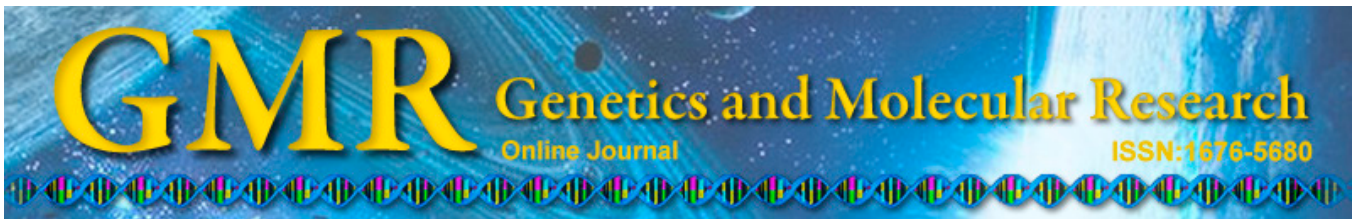

\title{
Common polymorphisms of the microRNA genes (miR-146a and miR-196a-2) and gastric cancer risk: an updated meta-analysis
}

\author{
Z.F. Chen ${ }^{1}$, L.L. Ma ${ }^{2}$ and H.B. Xue ${ }^{1}$ \\ ${ }^{1}$ The First Department of Gastroenterology, \\ The First Affiliated Hospital of Wenzhou Medical University, \\ Wenzhou, Zhejiang, China \\ ${ }^{2}$ Department of Rheumatology, \\ The First Affiliated Hospital of Wenzhou Medical University, \\ Wenzhou, Zhejiang, China \\ Corresponding author: H.B. Xue \\ E-mail: haibo_xue@yeah.net \\ Genet. Mol. Res. 14 (3): 8589-8601 (2015) \\ Received September 9, 2014 \\ Accepted April 6, 2015 \\ Published July 31, 2015 \\ DOI http://dx.doi.org/10.4238/2015.July.31.7
}

\begin{abstract}
The associations between two common polymorphisms in microRNA genes (miR-146a, dbSNP: rs2910164; miR-196a-2, dbSNP: rs11614913) and gastric cancer risk have frequently been examined; however, the results have often been controversial. This meta-analysis was performed to clarify the association between the two polymorphisms and gastric cancer risk. The literature search primarily utilized PubMed, Embase, SinoMed, and Wanfang databases to identify eligible studies. Odds ratios (ORs) with their 95\% confidence intervals (CIs) were analyzed to investigate possible correlations. Subgroup analyses of ethnicity as well as source of controls were also performed. The correlation analysis was based on 11 studies, containing 4690 patients and 6066 controls for miR-146a $(\mathrm{C}>\mathrm{G})$ together with 1911 patients and 2484 controls for miR-196a-2 $(\mathrm{T}>\mathrm{C})$. For the miR-146a polymorphism, the values of the ORs and $95 \%$ CIs were $>1$, suggesting
\end{abstract}


that a correlation exists. In subgroup analysis of source of controls, a correlation was also identified in the Asian subgroup. However, in Caucasians the ORs and $95 \%$ CIs were not distributed on the same side of the critical value 1 , contra-indicative of a correlation in this group. For the miR-196a-2 polymorphism, the ORs with $95 \%$ CIs of both overall and subgroup analyses were also not restricted to $>1$ or $<1$. In summary, the results suggested that the miR-146a rs2910164 polymorphism was related to gastric cancer risk in Asians but not in Caucasians, and no distinct correlation seemed to exist between the miR-196a-2 rs11614913 polymorphism and the risk of gastric cancer.

Key words: Gastric cancer; miR-146a; miR-196a-2; Polymorphism; Meta-analysis

\section{INTRODUCTION}

Gastric cancer is the fourth most common form of cancer, causing the second highest cancer-related mortality rate worldwide (Crew and Neugut, 2006). Approximately 989,600 new gastric cancer diagnoses together with 38,000 deaths were reported in 2008 (Jemal et al., 2011). The morbidity of gastric cancer varies with different regions, races, economic condition, and many other factors. For example, morbidity approximately doubles in males compared to females, and is more pervasive in the populations of Eastern Europe, Eastern Asia, and South America than those of North America and Africa (Jemal et al., 2011). In developing countries and in people with lower standards of living the incidence of distal gastric cancer is higher, while proximal tumors more frequently emerge in developed countries and in people with higher standards of living (Crew and Neugut, 2006). The progression of gastric cancer is a complex, multistage process and its occurrence is not only affected by environmental factors but also by genetic predisposition. In fact, three factors primarily give rise to gastric cancer: Helicobacter pylori infection, unhealthy diet such as intake of salted and smoked food, and epithelial cadherin (CDH1) mutations (Giordano and Cito, 2012).

MicroRNAs (miRNAs) belong to a type of noncoding RNAs approximately $22 \mathrm{nu}-$ cleotides in length. It has been demonstrated that this type of RNA plays an important part in many molecular interactions and regulates expression of certain genes as well as translation of messenger RNAs encoding protein factors in cells. miRNAs inhibit translation by pairing with certain parts of the mRNA, thus affecting biological processes including growth, metabolism, cell proliferation, differentiation, and apoptosis (Carrington and Ambros, 2003). These physiological processes are of great importance in the development of human life and disease. Abnormal expression of miRNAs is therefore also likely relevant to the growth of cancer. Recent research has suggested that miRNAs could be a regulatory factor in the process of gastric cancer progression (Yang et al., 2014). Evidence has also been presented that in the formation of tumors, miRNAs could become either suppressive or promoting factors (Esquela-Kerscher and Slack, 2006).

Single nucleotide polymorphisms (SNPs), located in coding or noncoding regions of a gene, occur most frequently among the diverse categories of genetic variation (Mahdi et al., 2013). Research has indicated that SNPs in miRNAs could be related to various types of 
tumors such as colorectal cancer (Kim et al., 2014). It has also been reported that SNPs in premiRNAs might influence the expression of miRNAs, thereby becoming indirectly involved in the development of cancers (Jazdzewski et al., 2008). Several SNPs in miRNA precursors (pre-miRNAs) have been identified. For this study, we selected two of the most frequently studied pre-miRNA SNPs: miR-146a $(\mathrm{C}>\mathrm{G})$ and miR-196a-2 $(\mathrm{T}>\mathrm{C})$.

To date, a number of studies have been conducted to evaluate the connections of miR146a and miR-196a-2 polymorphisms with gastric cancer risk. However, the conclusions have not always been in agreement. Some studies indicated that the GG genotype of miR-146a was possibly related to the augmentation of gastric cancer risk (Zeng et al., 2010; Hishida et al., 2011; Zhou et al., 2012a), while some suggested a relationship between the CC genotype and higher risk (Okubo et al., 2010). In addition, there have been studies showing no significant association between miR-146a and the development of gastric cancer (Ahn et al., 2012; Zhou et al., 2012b; Dikeakos et al., 2014; Kupcinskas et al., 2014; Pu et al., 2014). Similarly, for miR196a-2, some studies have suggested an association between the CC genotype and a higher gastric cancer risk (Okubo et al., 2010; Peng et al., 2010; Dikeakos et al., 2014), while some have implicated no such relationship (Ahn et al., 2012; Kupcinskas et al., 2014; Pu et al., 2014).

There have been previous meta-analyses studying the relationship between cancer risk and the two miRNA (miR-146a or miR-196a-2) polymorphisms. However, the number of included studies was somewhat limited. Some meta-analyses of miR-146a only included 3 or 4 case-control studies (Qiu et al., 2011; Wu et al., 2013; Li et al., 2014), and meta-analyses of miR-196a-2 contained only one or two studies (Guo et al., 2012; Zhang et al., 2012; Wang et al., 2013). Considering the controversial conclusions extant in the published studies and the limitations of previous meta-analyses, it is necessary that an updated meta-analysis be conducted that includes a larger sample size to measure the correlations of miR-146a and miR$196 \mathrm{a}-2$ with the risk of gastric cancer.

\section{MATERIAL AND METHODS}

\section{Eligible literature search}

Our literature search was developed in the PubMed, Embase, SinoMed, and Wanfang databases (last update: July 17, 2014) regarding studies related to miR-146a $(\mathrm{C}>\mathrm{G})$ together with miR-196a-2 $(\mathrm{T}>\mathrm{C})$ and gastric cancer. To identify all qualified studies, the following medical subject headings (MeSH) terms were searched: "miR-146a" or "rs2910164" or "miR196a-2" or "rs11614913" and "gastric cancer" or "gastric carcinoma" and "polymorphism" or "variant" or "allele" or "gene" or "single nucleotide polymorphism" or "SNP". We also retrieved the references and review articles to find other relevant publications. The whole process of selection is illustrated in Figure 1.

\section{Selection criteria}

The following criteria were applied to select eligible studies: a) use of case-control study design; $b$ ) evaluated the relationship between gastric cancer and polymorphisms of miR146a or miR-196a-2; c) genotype distribution in control groups met Hardy-Weinberg equilibrium (HWE); and d) authentic genotype frequencies were provided. The exclusion criteria were: a) multiple publications; b) lack of control groups; c) meta-analysis, review, editorial, 
and comment; and d) incomplete data. When the same sample population was surveyed in multiple publications, we chose the newest or the largest-sized studies.

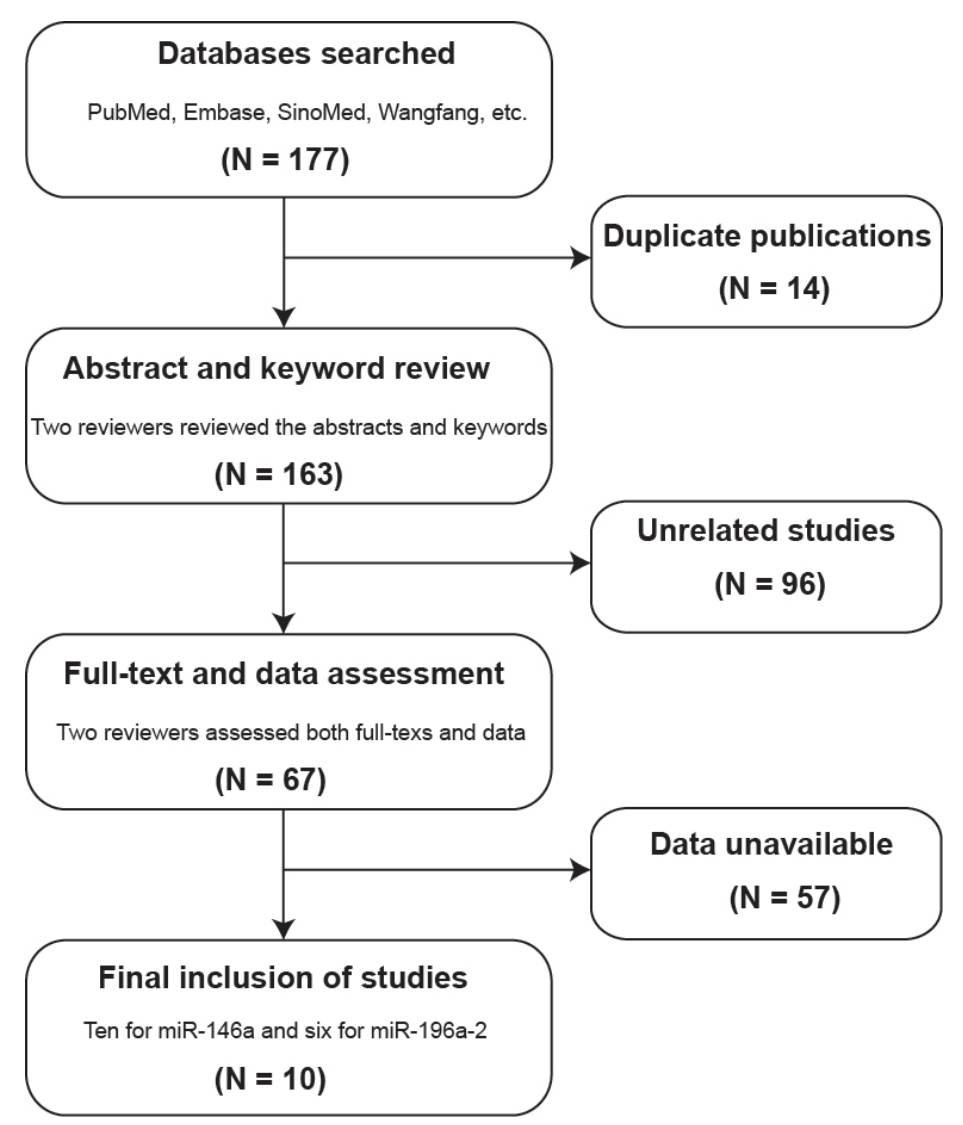

Figure 1. Flow diagram of the selection procedure and exclusion criteria.

\section{Data extraction}

The following information was extracted from each study: first author's name; year of publication; country and ethnicity of the studied population; source of controls; number, mean age, and gender of subjects studied; detection method; genotype frequencies of patients together with controls. These data were first extracted by two investigators independently (Z.F. Chen and L.L. Ma) and then contrasted. If any discrepancy occurred, another investigator would be required to check prudently in the original literature.

\section{Quality assessment}

In order to score the quality of the studies included, the Strengthening the Reporting of Observational Studies in Epidemiology (STROBE) quality score system was applied (von 
Elm et al., 2007). The 22 items in the guide list of the STROBE statement were checked by two investigators independently (Z.F. Chen and L.L. Ma) for each study. Based on the answers to the items, the quality of a study was considered moderate to high if it received a score over 14. The included studies met this standard.

\section{Statistical analysis}

HWE of the genotype distributions in the control groups were evaluated via the chisquare test in each study. When the P value of HWE was more than 0.05 , the genotypes of the control group reached the required standard. All the studies we analyzed in the meta-analysis met this standard (Table 1). Association was measured considering ORs and their $95 \% \mathrm{CIs}$, which were calculated under five genetic models (wherein $\mathrm{W}$ was substituted for the wildtype allele and $\mathrm{M}$ for the mutant allele): the allelic model ( $\mathrm{M} v s \mathrm{~W}$ alleles), the dominant model (MM+WM vs WW), the recessive model (MM vs WW+WM), the homozygous model $(\mathrm{MM} v s \mathrm{WW})$, and the heterozygous model (MM vs WM). When analyzing the heterogeneity of these included studies, we conducted a Q-statistic test based on chi-square (Higgins and Thompson, 2002), and a $\mathrm{P}$ value of $<0.05$ indicated heterogeneity among the different studies. Pooled ORs were assessed through a random-effect model (DerSimonian-Laird method) when heterogeneity appeared (DerSimonian and Laird, 1986). Otherwise a fixedeffect model (Mantel-Haenszel method) was applied (Mantel and Haenszel, 1959). Subgroup analyses of the two miRNA polymorphisms based on ethnicity (Caucasian and Asian) and the source of controls (population- and hospital-based case-control studies) were also performed. Sensitivity was analyzed to examine whether the results were substantially influenced by any single study. Both Begg's funnel plot of ORs and the Egger test were utilized to determine publication bias. All the tests of analysis utilized the Stata software version 12.0 (Stata Corp., College Station, TX, USA).

\section{RESULTS}

\section{Characteristics of studies}

In summary, this meta-analysis included 11 qualified studies (Okubo et al., 2010; Peng et al., 2010; Zeng et al., 2010; Hishida et al., 2011; Ahn et al., 2012; Ma and Zheng, 2012; Zhou et al., 2012a,b; Dikeakos et al., 2014; Kupcinskas et al., 2014; Pu et al., 2014). Among these, 10 articles containing 4690 patients and 6066 controls studied the correlation between miR-146a and gastric cancer risk. Two were carried out in Caucasian and eight in Asian populations. Four utilized a population-based case-control study design (PCC) and six were hospital-based case-control studies (HCC). For miR-196a-2, six studies involving 1911 patients and 2484 controls were examined, of which two were conducted in Caucasian and four in Asian populations. Of the six studies, three were PCC and three were HCC. Overall, seven studies used the classic detection method of polymerase chain reaction-restriction fragment length polymorphism (PCR-RFLP), two used TaqMan, one used MassARRAY and the other one used qRT-PCR. All the control genotype distributions met the requirements of HWE. Explicit data are listed in Table 1. Results of the associations of miR-146a and miR-196a-2 with susceptibility to gastric cancer are listed in Table 2. 
Z.F. Chen et al.

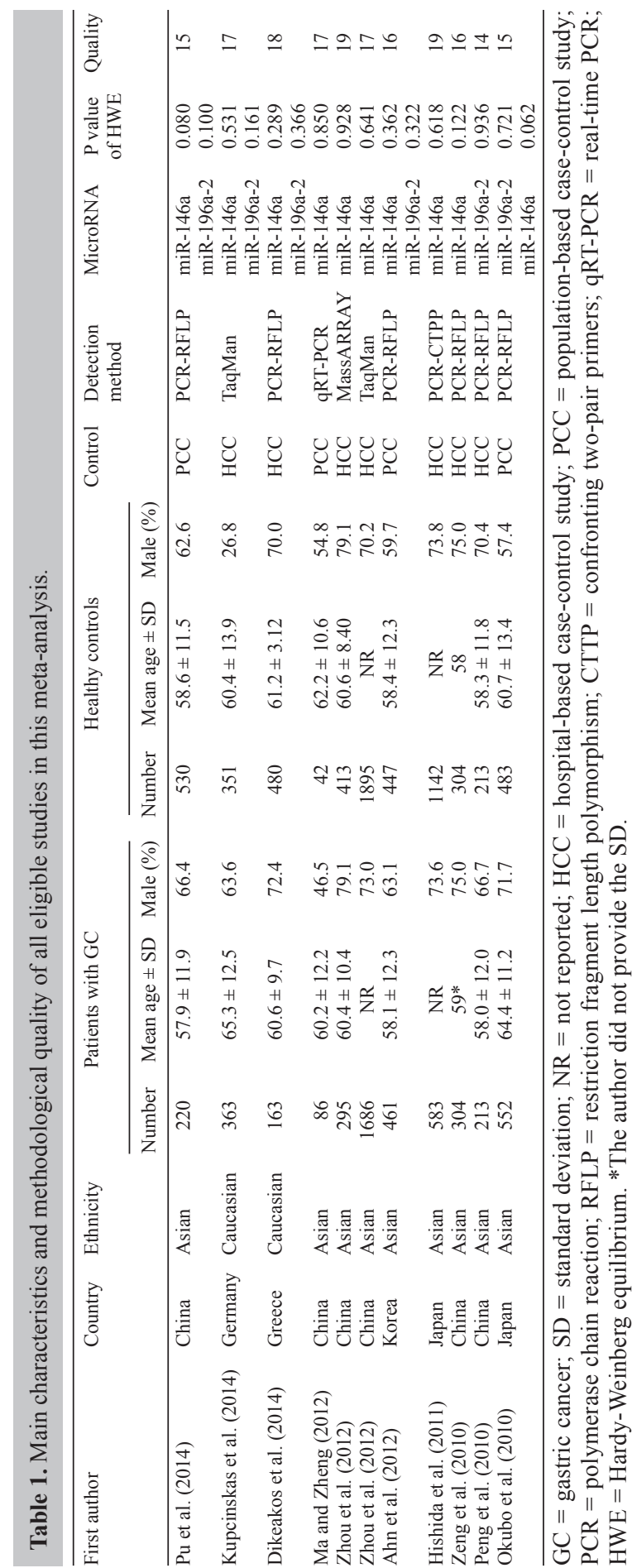




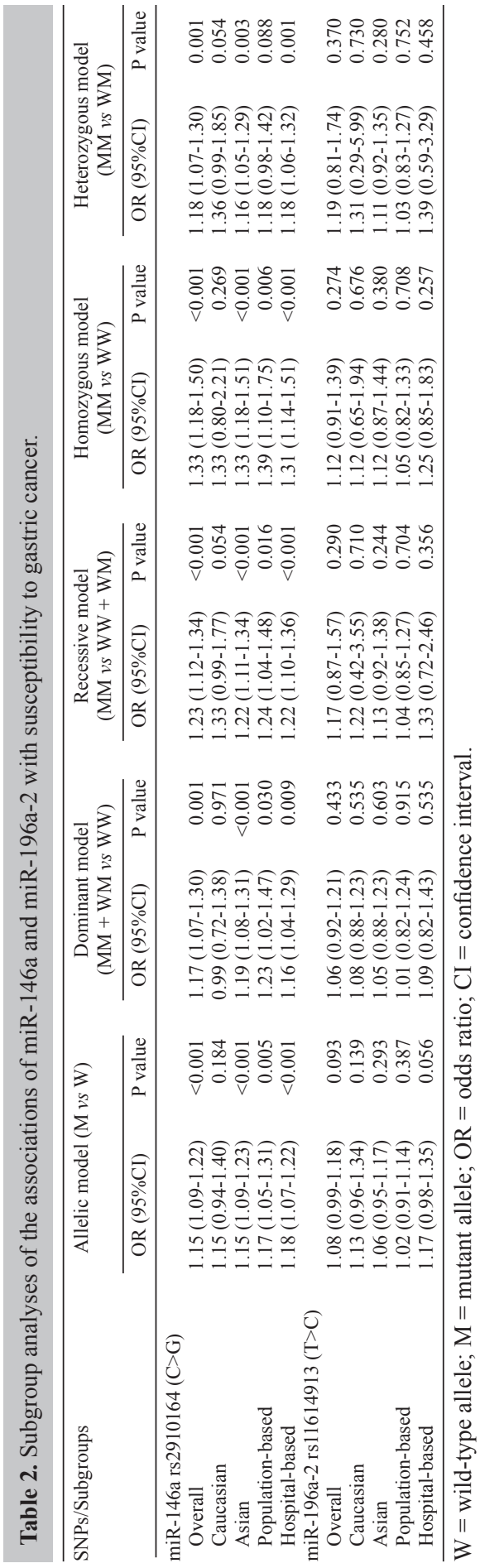




\section{Association between miR-146a rs2910164 (C>G) and gastric cancer risk}

When the statistics in the 10 studies were combined, the $\mathrm{P}$ values in the five gene models were all $<0.05$, indicating that there might be a relationship between the rs 2910164 polymorphism and gastric cancer risk, and that the $\mathrm{G}$ allele might be a risk factor for gastric cancer ( $\mathrm{G}$ allele $v_{s} \mathrm{C}$ allele: $\mathrm{OR}=1.15,95 \% \mathrm{CI}=1.09-1.22, \mathrm{P}<0.001 ; \mathrm{GG}+\mathrm{CG}$ vs $\mathrm{CC}$ : OR $=1.17,95 \% \mathrm{CI}=1.07-1.30, \mathrm{P}=0.001 ; \mathrm{GG}$ vs $\mathrm{CC}+\mathrm{CG}: \mathrm{OR}=1.23,95 \% \mathrm{CI}=1.12-1.34, \mathrm{P}<$ 0.001 ; GG vs $\mathrm{CC}: \mathrm{OR}=1.33,95 \% \mathrm{CI}=1.18-1.50, \mathrm{P}<0.001$; $\mathrm{GG}$ vs $\mathrm{CG}: \mathrm{OR}=1.18,95 \% \mathrm{CI}$ $=1.07-1.30, \mathrm{P}=0.001)$. In sub-analysis stratified by source of controls, both the populationand the hospital-based subgroups suggested similar relationships. In contrast, the sub-analysis of ethnicity showed a different result. In the Caucasian subgroup, no significant association seemed to exist between miR-146a $(\mathrm{C}>\mathrm{G})$ and gastric cancer risk $(\mathrm{G}$ allele $v$ s $\mathrm{C}$ allele: $\mathrm{OR}=$ $1.15,95 \% \mathrm{CI}=0.94-1.40, \mathrm{P}=0.184 ; \mathrm{GG}+\mathrm{CG}$ vs $\mathrm{CC}: \mathrm{OR}=0.99,95 \% \mathrm{CI}=0.72-1.38, \mathrm{P}=0.971$; GG $v s \mathrm{CC}+\mathrm{CG}: \mathrm{OR}=1.33,95 \% \mathrm{CI}=0.99-1.77, \mathrm{P}=0.054 ; \mathrm{GG} v s \mathrm{CC}: \mathrm{OR}=1.33,95 \% \mathrm{CI}=$ $0.80-2.21, \mathrm{P}=0.269 ; \mathrm{GG} v s \mathrm{CC}: \mathrm{OR}=1.36 ; 95 \% \mathrm{CI}=1.05=1.29, \mathrm{P}=0.054)$, while analysis of the Asian subgroup suggested that the $\mathrm{G}$ allele might be associated with a higher gastric cancer risk ( $\mathrm{G}$ allele $v s \mathrm{C}$ allele: $\mathrm{OR}=1.15,95 \% \mathrm{CI}=1.09-1.23, \mathrm{P}<0.001 ; \mathrm{GG}+\mathrm{CG} v s \mathrm{CC}: \mathrm{OR}=1.19$, $95 \% \mathrm{CI}=1.08-1.31, \mathrm{P}<0.001 ; \mathrm{GG}$ vs $\mathrm{CC}+\mathrm{CG}: \mathrm{OR}=1.22,95 \% \mathrm{CI}=1.11-1.34, \mathrm{P}<0.001 ; \mathrm{GG}$ vs $\mathrm{CC}: \mathrm{OR}=1.33,95 \% \mathrm{CI}=1.18-1.51, \mathrm{P}<0.001 ; \mathrm{GG}$ vs $\mathrm{CC}: \mathrm{OR}=1.16,95 \% \mathrm{CI}=1.05-1.29$, $\mathrm{P}=0.003)$. Specific data for each study in this sub-analysis are illustrated in Figure 2.
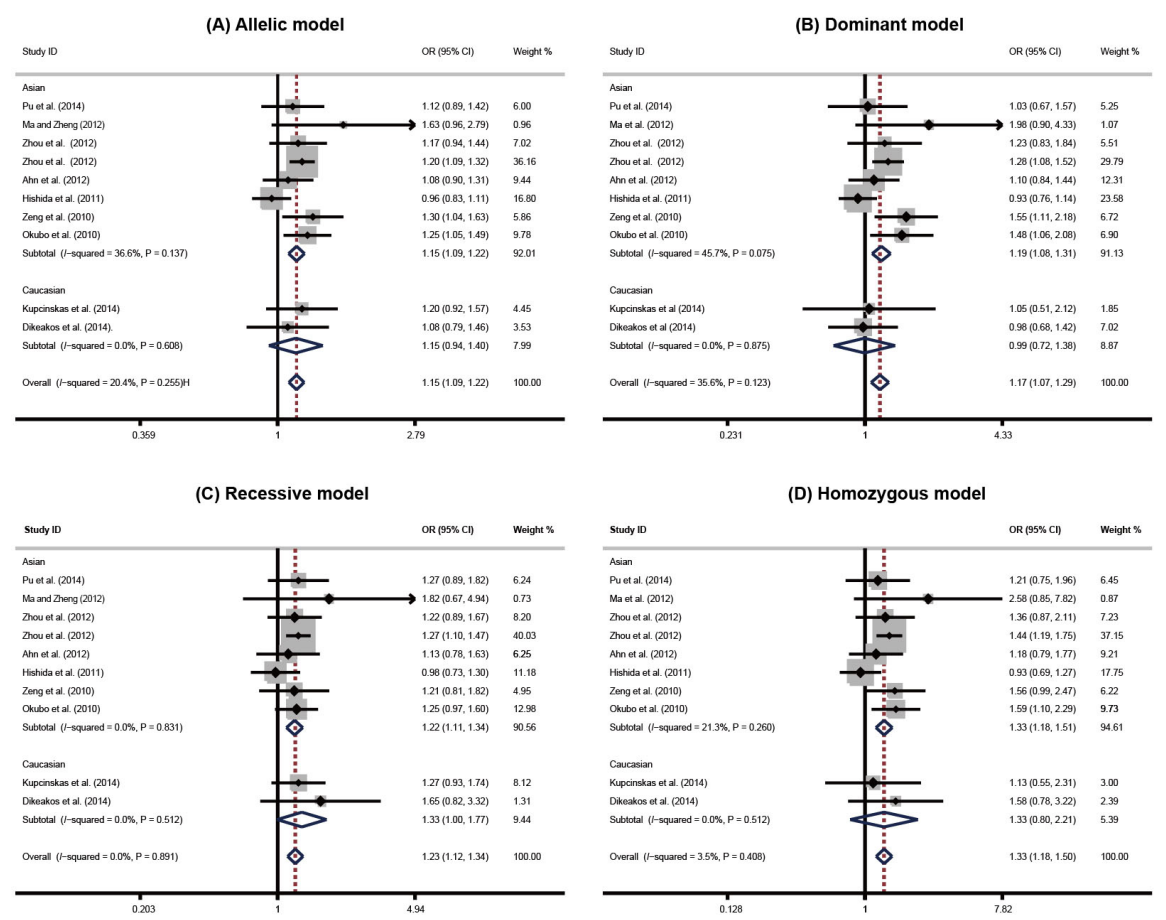

Figure 2. Forest plots of the odds ratios for the association between the miR-146a polymorphism and gastric cancer risk in subgroup analysis of ethnicity, adopting: A. G vs C; B. GG+CG $v_{s} \mathrm{CC}$; C. GG $v_{s} \mathrm{CC}+\mathrm{CG}$; and D. GG $v_{s} \mathrm{CC}$. $\mathrm{OR}=$ odds ratio $\mathrm{CI}=$ confidence interval. 


\section{Association between miR-196a-2 rs11614913 $(\mathrm{T}>\mathrm{C})$ and gastric cancer risk}

For the miR-196a-2 ( $>$ C $)$ polymorphism, no distinct association was identified with gastric cancer risk under any of the five genetic models ( $\mathrm{C}$ allele $v_{s} \mathrm{~T}$ allele: $\mathrm{OR}=1.08,95 \% \mathrm{CI}$ $=0.99-1.18, \mathrm{P}=0.093 ; \mathrm{CC}+\mathrm{TC}$ vs TT: $\mathrm{OR}=1.06,95 \% \mathrm{CI}=0.92-1.21, \mathrm{P}=0.433 ; \mathrm{CC}$ vs TT+TC: $\mathrm{OR}=1.17,95 \% \mathrm{CI}=1.87-1.57, \mathrm{P}=0.290 ; \mathrm{CC} v s \mathrm{TT}: \mathrm{OR}=1.12,95 \% \mathrm{CI}=0.91-1.39$, $\mathrm{P}=0.274 ; \mathrm{CC}$ vs $\mathrm{TC}: \mathrm{OR}=1.19,95 \% \mathrm{CI}=0.81-1.74, \mathrm{P}=0.370$ ); neither did the subgroup analyses of ethnicity or source of controls show a relationship between the miR-196a-2 polymorphism and gastric cancer risk.

\section{Sensitivity analysis and publication bias}

We examined the sensitivity of the data by omitting a single study and analyzing the remainder. Figure 3A and B shows the results of miR-146a and miR-196a-2 sensitivity analyses, respectively. As the meta-analysis estimates were relatively stable, we might thus conclude that the overall results were not substantially impacted by one study alone and were therefore credible. Publication bias was tested via Begg's funnel plots together with the Egger linear regression test in the allelic model. For miR-146a, statistical results showed $\mathrm{P}=0.788$ in the Begg test and $t=1.61, \mathrm{P}=0.145$ in the Egger test (Figure $4 \mathrm{~A}$ ); for miR-196a-2, $\mathrm{P}=0.851$ in the Begg test and $t=0.52, \mathrm{P}=0.630$ in the Egger test (Figure 4B). Neither of the results indicated any evidence of significant publication bias.
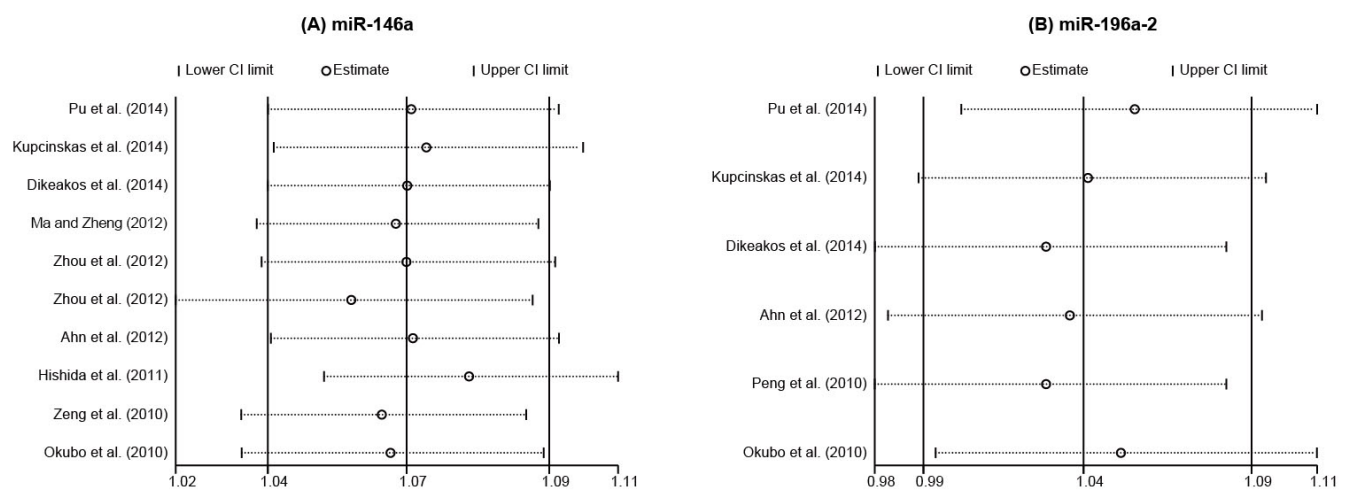

Figure 3. Sensitivity analysis of all eligible studies. A. miR-146a; B. miR-196a-2. CI = confidence interval.

\section{DISCUSSION}

To date, over 900 human miRNA genes have been discovered and registered in miRBase, and studies have suggested that miRNAs are regulators in the expression process of over one-third of all human genes (Kwak et al., 2010). miRNAs can target sites of mRNAs and repress their post-transcriptional processing through generation into a form of silencing complex (i.e., the RNA-induced silencing complex) (Friedman et al., 2009). Through the wide range of their effects, miRNAs are thus associated with various cancers. SNPs in different regions of miRNA genes can affect the function of the miRNAs through various mechanisms 


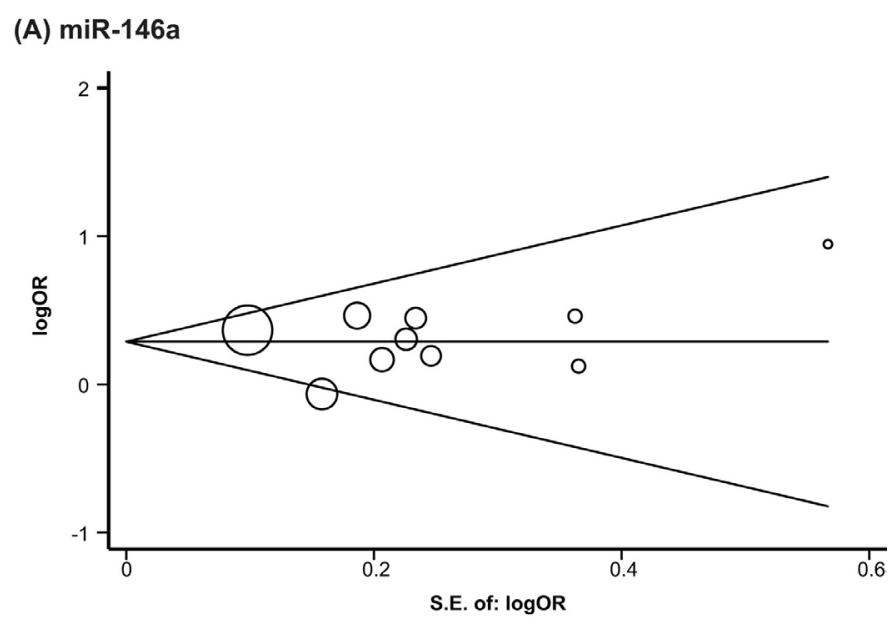

(B) miR-196a-2

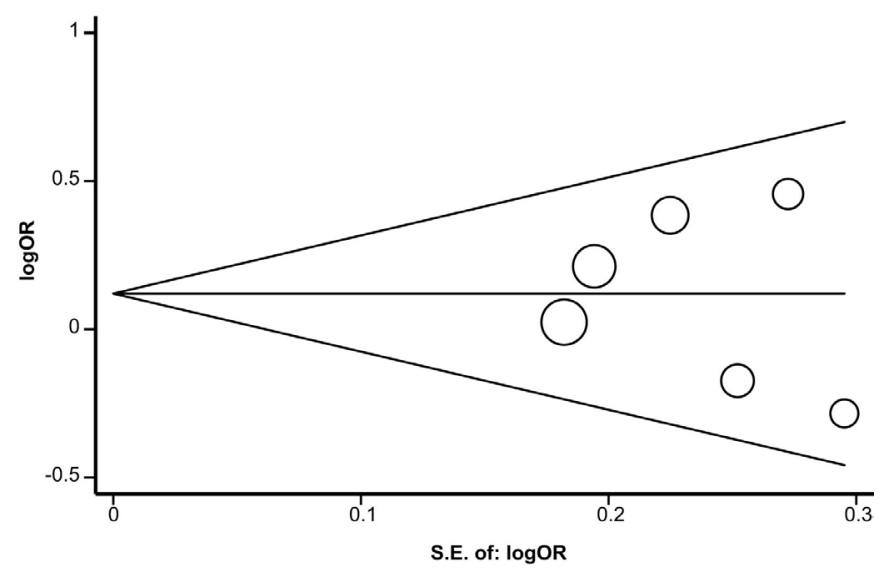

Figure 4. Begg's funnel plots to identify publication bias of the studies included. A. miR-146a; B. miR-196a-2. S.E. $=$ standard error.

(Ryan et al., 2010). Considerable evidence has suggested that mutations in miRNA genes might affect risk of cancers such as chronic lymphocytic leukemia (Calin et al., 2005), and cervical (Zhou et al., 2010), bladder, breast (Teo et al., 2012), and colorectal cancers (Kim et al., 2014), among others. Thus, it appeared likely that polymorphisms of miR-146a and miR196a-2 might have some influence on human gastric carcinoma. Indeed, some studies have revealed that a relationship between the two polymorphisms of miR-146a and miR-196a-2 and gastric cancer might exist. However, the results overall have not led to a definitive conclusion. This meta-analysis was an attempt to address the problem through combination of the data from these studies to increase statistical power.

Overall, our meta-analysis included 11 qualified studies. From the combined data, we found that the G allele and the GG genotype of the miR-146a polymorphism were related 
to a higher risk of gastric cancer. In subgroup analysis, we explored whether the relationship was affected by other characteristics of the study, and drew similar conclusions in groups of sub-analysis stratified by source of controls. When it came to ethnicity, however, we obtained different results. We found no significant association between miR-146a variants among Caucasians whereas the G allele or GG genotype of the miR-146a polymorphism were suggested to constitute a risk factor for gastric cancer in Asians. The conclusion was not influenced by source of controls. In contrast, our results found that the polymorphism in miR-196a-2 might not be related to either an increase or a decrease in the susceptibility to gastric cancer. It has previously been shown that miR-146a is involved in various cell activities. Through its two targets, TRAF6 and IRAK1, miR-146a can inhibit the function of immune cell thereby affecting the human innate immune system (Taganov et al., 2006). Furthermore, the miR-146a gene was reported to down-regulate NF- $\mathrm{kB}$, suppress cell proliferation, and induce apoptosis, and therefore might function as a potent tumor suppressor (Paik et al., 2011). Mutation of the $m i R$ $146 a$ gene may impair these functions; therefore the mutant allele might augment the risk of developing gastric cancer, in concordance with our results.

Gastric cancer development is affected by multiple factors including infectious agents such as $H$. pylori, genes and their expression, living habits such as alcohol, smoking and eating habits (Asombang et al., 2014), among others, and it varies in different regions and ethnic groups. For instance, in the United States, gastric cancer emerges more often in Native Americans, Hispanics, and African Americans than in Caucasians (Piazuelo and Correa, 2013). Therefore, the difference found in our study between Asians and Caucasians might be due to different genetic components, different dietary and other living habits, economic conditions, or different environments, which might influence the susceptibility to $H$. pylori infection and overall health.

However, several limitations existed in the meta-analysis, potentially qualifying our conclusions. First, the sample size of the Caucasian subgroup might not be large enough to yield a definitive conclusion, and not all the Caucasians in the different regions were sampled to survey. Second, the Asian and Caucasian populations in the studies could be distinct in many aspects besides ethnicity, such as living regions or socioeconomic status, which were beyond the control of the analysis. Therefore, we could not attribute the differing results between these populations solely to ethnicity, without failing to make the potential factor effect clear. Third, the differences in stages and types of gastric cancer were not taken into account as the data about these factors in the included studies were not sufficient. That these variables were dismissed during analysis might reduce the accuracy of the conclusions. Despite the defects listed above, this meta-analysis incorporated with previous studies, and analyzed a greater amount data than have other meta-analyses of the same purpose, which will help to elucidate the exact relationship between the two microRNA polymorphisms and the susceptibility to gastric cancer. Further studies with larger sample sizes and more rigorous designations should be conducted to clarify the association between the two polymorphisms and gastric cancer risk.

In summary, the $\mathrm{G}$ allele of the miR-146a polymorphism might be a candidate for a risk factor of gastric cancer in Asians, but no such association appears to exist in Caucasians. In contrast, miR-196a-2 polymorphism might not be significantly related to gastric cancer risk. The specific mechanism of the identified association also requires more exploration. 


\section{REFERENCES}

Ahn DH, Rah H, Choi YK, Jeon YJ, et al. (2012). Association of the miR-146aC $>$ G, miR-149T $>$ C, miR-196a2T $>$ C, and miR-499A $>\mathrm{G}$ polymorphisms with gastric cancer risk and survival in the Korean population. Mol. Carcinog. 52: E39-51.

Asombang AW, Rahman R and Ibdah JA (2014). Gastric cancer in Africa: current management and outcomes. World J. Gastroenterol. 20: 3875-3879.

Calin GA, Ferracin M, Cimmino A, Di Leva G, et al. (2005). A microRNA signature associated with prognosis and progression in chronic lymphocytic leukemia. N. Engl. J. Med. 353: 1793-1801.

Carrington JC and Ambros V (2003). Role of microRNAs in plant and animal development. Science 301: 336-338.

Crew KD and Neugut AI (2006). Epidemiology of gastric cancer. World J. Gastroenterol. 12: 354-362.

DerSimonian R and Laird N (1986). Meta-analysis in clinical trials. Control. Clin. Trials 7: 177-188.

Dikeakos P, Theodoropoulos G, Rizos S, Tzanakis N, et al. (2014). Association of the miR-146aC $>$ G, miR-149T $>$ C, and miR-196a2T $>$ C polymorphisms with gastric cancer risk and survival in the Greek population. Mol. Biol. Rep. 41: 1075-1080.

Esquela-Kerscher A and Slack FJ (2006). Oncomirs - microRNAs with a role in cancer. Nat. Rev. Cancer 6: 259-269.

Friedman RC, Farh KK, Burge CB and Bartel DP (2009). Most mammalian mRNAs are conserved targets of microRNAs. Genome Res. 19: 92-105.

Giordano A and Cito L (2012). Advances in gastric cancer prevention. World J. Clin. Oncol. 3: 128-136.

Guo J, Jin M, Zhang M and Chen K (2012). A genetic variant in miR-196a2 increased digestive system cancer risks: a meta-analysis of 15 case-control studies. PLoS One 7: e30585.

Higgins JP and Thompson SG (2002). Quantifying heterogeneity in a meta-analysis. Stat. Med. 21: 1539-1558.

Hishida A, Matsuo K, Goto Y, Naito M, et al. (2011). Combined effect of miR-146a rs2910164 G/C polymorphism and Toll-like receptor $4+3725$ G/C polymorphism on the risk of severe gastric atrophy in Japanese. Dig. Dis. Sci. 56: 1131-1137.

Jazdzewski K, Murray EL, Franssila K, Jarzab B, et al. (2008). Common SNP in pre-miR-146a decreases mature miR expression and predisposes to papillary thyroid carcinoma. Proc. Natl. Acad. Sci. U. S. A. 105: 7269-7274.

Jemal A, Bray F, Center MM, Ferlay J, et al. (2011). Global cancer statistics. CA Cancer J. Clin. 61: 69-90.

Kim JG, Chae YS, Lee SJ, Kang BW, et al. (2014). Genetic variation in microRNA-binding site and prognosis of patients with colorectal cancer. J. Cancer Res. Clin. Oncol. [Epub ahead of print].

Kupcinskas J, Wex T, Link A, Leja M, et al. (2014). Gene polymorphisms of microRNAs in Helicobacter pylori-induced high risk atrophic gastritis and gastric cancer. PLoS One 9: e87467.

Kwak PB, Iwasaki S and Tomari Y (2010). The microRNA pathway and cancer. Cancer Sci. 101: 2309-2315.

Li YJ, Zhang ZY, Mao YY, Jin MJ, et al. (2014). A genetic variant in MiR-146a modifies digestive system cancer risk: a meta-analysis. Asian Pac. J. Cancer Prev. 15: 145-150.

Ma B and Zheng JZ (2012). Correlation analysis of microRNA-146a gene polymorphism and gastric cancer. Chin. J. Gerontol. 32: 3150-3152.

Mahdi KM, Nassiri MR and Nasiri K (2013). Hereditary genes and SNPs associated with breast cancer. Asian Pac. J. Cancer Prev. 14: 3403-3409.

Mantel N and Haenszel W (1959). Statistical aspects of the analysis of data from retrospective studies of disease. J. Natl. Cancer Inst. 22: 719-748.

Okubo M, Tahara T, Shibata T, Yamashita H, et al. (2010). Association between common genetic variants in premicroRNAs and gastric cancer risk in Japanese population. Helicobacter 15: 524-531.

Paik JH, Jang JY, Jeon YK, Kim WY, et al. (2011). MicroRNA-146a downregulates NFkappaB activity via targeting TRAF6 and functions as a tumor suppressor having strong prognostic implications in NK/T cell lymphoma. Clin. Cancer Res. 17: 4761-4771.

Peng S, Kuang Z, Sheng C, Zhang Y, et al. (2010). Association of microRNA-196a-2 gene polymorphism with gastric cancer risk in a Chinese population. Dig. Dis. Sci. 55: 2288-2293.

Piazuelo MB and Correa P (2013). Gastric cancer: Overview. Colomb. Med. 44: 192-201.

$\mathrm{Pu}$ JY, Dong W, Zhang L, Liang WB, et al. (2014). No association between single nucleotide polymorphisms in premiRNAs and the risk of gastric cancer in Chinese population. Iran. J. Basic Med. Sci. 17: 128-133.

Qiu LX, He J, Wang MY, Zhang RX, et al. (2011). The association between common genetic variant of microRNA-146a and cancer susceptibility. Cytokine 56: 695-698.

Ryan BM, Robles AI and Harris CC (2010). Genetic variation in microRNA networks: the implications for cancer research. Nat. Rev. Cancer 10: 389-402. 
Taganov KD, Boldin MP, Chang KJ and Baltimore D (2006). NF-kappaB-dependent induction of microRNA miR-146, an inhibitor targeted to signaling proteins of innate immune responses. Proc. Natl. Acad. Sci. U. S. A. 103: 12481-12486.

Teo MT, Landi D, Taylor CF, Elliott F, et al. (2012). The role of microRNA-binding site polymorphisms in DNA repair genes as risk factors for bladder cancer and breast cancer and their impact on radiotherapy outcomes. Carcinogenesis 33: 581-586.

von Elm E, Altman DG, Egger M, Pocock SJ, et al. (2007). The strengthening the reporting of observational studies in epidemiology (STROBE) statement: guidelines for reporting observational studies. Lancet 370: 1453-1457.

Wang F, Sun GP, Zou YF, Fan LL, et al. (2013). Quantitative assessment of the association between miR-196a2 rs11614913 polymorphism and gastrointestinal cancer risk. Mol. Biol. Rep. 40: 109-116.

Wu D, Wang F, Dai WQ, He L, et al. (2013). The miR-146a rs2910164 G > C polymorphism and susceptibility to digestive cancer in Chinese. Asian Pac. J. Cancer Prev. 14: 399-403.

Yang O, Huang J and Lin S (2014). Regulatory effects of miRNA on gastric cancer cells. Oncol. Lett. 8: 651-656.

Zeng Y, Sun QM, Liu NN, Dong GH, et al. (2010). Correlation between pre-miR-146a C/G polymorphism and gastric cancer risk in Chinese population. World J. Gastroenterol. 16: 3578-3583.

Zhang H, Su YL, Yu H and Qian BY (2012). Meta-analysis of the association between Mir-196a-2 polymorphism and cancer susceptibility. Cancer Biol. Med. 9: 63-72.

Zhou F, Zhu H, Luo D, Wang M, et al. (2012a). A functional polymorphism in pre-miR-146a is associated with susceptibility to gastric cancer in a Chinese population. DNA Cell Biol. 31: 1290-1295.

Zhou X, Chen X, Hu L, Han S, et al. (2010). Polymorphisms involved in the miR-218-LAMB3 pathway and susceptibility of cervical cancer, a case-control study in Chinese women. Gynecol. Oncol. 117: 287-290.

Zhou Y, Du WD, Chen G, Ruan J, et al. (2012b). Association analysis of genetic variants in microRNA networks and gastric cancer risk in a Chinese Han population. J. Cancer Res. Clin. Oncol. 138: 939-945. 